\title{
The nutrition transition and its health implications in lower-income countries
}

\author{
Barry M Popkin * \\ Department of Nutrition, University of North Carolina at Chapel Hill, North Carolina, USA
}

Submitted 17 Odober 1997: Accepted 29 November 1997

\begin{abstract}
Objective. This article reviews information on the rapid changes in diet, activity and body composition that lower- and middle-income countries are undergoing and then examines some of the potential health implications of this transition.

Design and Setting: Data came from numerous countries and also from national food balance (FAOSTAT) and World Bank sources. Nationally representative and nationwide surveys are used. The nationally representative Russian Longitudinal Monitoring Surveys from 1992-96 and the nationwide China Health and Nutrition Survey from 1989-93 are examined in detail.

Results: Rapid changes in the structure of diet, in particular associated with urbanization, are documented. In addition, large changes in occupation types are documented. These are linked with rapid increases in adult obesity in Latin America and Asia. Some of the potential implications for adult health are noted.

Conclusions. The rapid changes in diet, activity and obesity that are facing billions of residents of lower- and middle-income countries are cause for great concern. Linked with these changes will be a rapid increase in chronic diseases. Little to date has been done at the national level to address these problems.
\end{abstract}

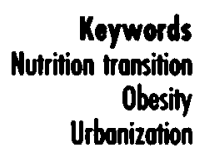

Human history is characterized by a series of changes in diet and nutritional status. This pace of change has quickened considerably over the last three centuries ${ }^{1,2}$. Before that, major changes in diet and nutritional status occurred infrequently and one could argue that there were relatively few changes in diet for the first several million years of existence of the human race. This article focuses mainly on current stages in the nutrition transition. The concept of transitions or movement from one state or condition to another is used to capture the dynamic nature of diet, particularly large shifts in its overall structure. Many of the same factors that explain shifts in diet also explain those in physical activity and body composition. This work is based on the premise that the transition to the age of degenerative diseases is avoidable and that an understanding of the patterns and sources of change will serve as a basis for future interventions at the population level to lead to more healthful transitions.

A similar concept of transitions is embodied in the theory of the demographic transition - the shift from a pattern of high fertility and mortality (typical of less developed countries decades ago and of eighteenthcentury Europe) to one of low fertility and mortality (typical of modern industrialized nations today). Even more directly relevant is the concept of the epidemiological transition, which focuses on changes in patterns of disease and causes of mortality. As first conceptualized by $\mathrm{Omran}^{3}$, the epidemiological transition moves from a pattern of a high prevalence of infectious diseases and malnutrition to one in which chronic and degenerative diseases predominate. Accompanying this progression from an earlier stage of pestilence, famine and poor environmental sanitation to the later stage of chronic and degenerative diseases strongly associated with life-style, is a major shift in age-specific mortality patterns and life expectancy. Both of these concepts of transitions share a focus on how populations move from one stage or condition to the next.

There have been large changes over time in diet and physical activity, especially their structure and overall composition. These changes are reflected in nutritional outcomes such as stature and body composition. Furthermore, these changes are paralleled by changes in life-style and health status, as well as by major demographic and socioeconomic changes. For example, during the early stages of human evolution (from about 3 million to about 10 thousand years ago), human subsistence was based primarily on a pattern of gathering, scavenging and hunting. The diet these early humans consumed was varied, low in fat and high in fibre. Physical activity levels were high. In consequence, early Homo sapien hunter-gatherers tended to be taller and more robust, and suffered fewer nutritional deficiencies than humans who lived in 
settled communities during the period of early agriculture. These early agriculturalists' diet was much simpler and subject to tremendous fluctuations. After 10-12 thousand years of this second stage, the Industrial Revolution and a second agricultural revolution led to a considerable reduction of problems of famine, large shifts in diet and increased stature. This period was followed by a marked shift to the high-fat, refined carbohydrate, low-fibre diet which marks most high-income societies today. Also, an increase in obesity and all the degenerative diseases of Omran's final stage occurred. There is some indication that a new stage of behavioural change related to the reaction to man-made diseases is occurring in selected populations. These five periods are:

- the age of collecting food,

- the age of famine,

- the age of receding famine,

- the age of degenerative diseases, and

- the age of behavioural change.

For this article, I focus mainly on the periods that relate to the circumstances most lower- and middle-income countries face - that is, a period where famine has receded and degenerative diseases are rapidly emerging.

The theory of the nutrition transition posits that these changes or stages relate to the complex interplay of changes in patterns of agricultural, health and socioeconomic factors, among others (for further detail see Popkin ${ }^{1,2}$ ). For this article, the major issues that are considered are demographic and economic changes.

The emergence in the last quarter of the twentieth century of obesity as an epidemic among higherincome countries is acknowledged and has been of great concern in these countries. While the specific effects of the shifts in the patterns of diet and activity vary from population to population, both are important. We now face the emergence of obesity as a worldwide phenomenon affecting the rich and middleincome people alike in middle-income countries and also affecting countries previously considered to be poor. This emergence and prevalence of obesity, with all its related health complications, is felt to have major health complications. I note later in the article that this obesity epidemic has been linked in low- and middle-income countries with a rapid increase in the prevalence, as well as earlier age for the onset, of noninsulin-dependent diabetes mellitus (NIDDM). Other well-known complications of excess adiposity which are not discussed include coronary heart disease, many cancers and a large proportion of disabling osteoarthritis.

The attention given by the food and nutrition communities in countries such as China, Brazil and many lower-income countries has focused on problems of undernutrition but information is presented here to indicate an emerging paradigm with obesity being the dominant problem or with an ever-increasing obesity problem coexisting with one of dietary deficit. Furthermore, these rapid shifts in obesity, caused by shifts in diet and activity, are linked with rapid increases in NIDDM and other related chronic diseases. This increase is found in countries whose populations are more genetically susceptible and in other nations. This combination of very rapid shifts in diet and activity and the emergence at very early stages of economic improvement of high rates of chronic disease forces us to focus attention on this topic.

After a brief introduction to the data and measures, the article first introduces the major underlying social and demographic changes, then the dietary and physical activity changes, followed by a discussion of the evidence of the obesity epidemic and NIDDM as it relates to this transition.

\section{Methods}

\section{Data}

Data came from a large number of sources, mainly nationally representative or large nationwide surveys. In addition I use national data sets such as food balance sheets and national income accounts.

A thorough presentation is made of the China Health and Nutrition Survey (CHNS), an on-going, longitudinal survey of eight provinces in China. A multistage, random, cluster sampling procedure was used to draw the sample from each province. Additional detail on the research design of this survey is presented elsewheres.

For some of the information on obesity patterns and trends, the focus is mainly on larger and more representative samples of adults. Our selection criteria for presenting data from other surveys was size, sampling design and geographic area. If a study was representative of a region or country, it was always used. If it came from a region with few studies and did not fit the criteria of national representativeness, I used it if the sample size was large and it seemed reasonably representative. Note that I use the term region only to fit a cluster of countries and not an area within a country.

National food consumption data came from the Food and Agriculture Organization of the United Nations (FAO) food balance sheets for the period 1962-90, now available in the FAOSTAT database ${ }^{6}$. Data on food availability is combined to express in percentage terms daily energy from macronutrients, with the official estimates of gross national product (GNP), as established by the World Bank. 


\section{Measures}

For the national food consumption and economic pattern analysis, GNP per capita was expressed in 1993 American dollars to allow for an easier comparison of the results. Regression analyses were used to relate dietary data (the proportion of energy from vegetable and animal fats, carbohydrates, caloric sweeteners and protein) for those countries for which full sets of data were available in 1962 and in 1990 to the logarithm of per capita GNP. This research used all countries for which both sets of data were available - 98 in 1962 and 133 in 1990 . These results were not changed when looking only at a set of countries with full sets of data in both 1962 and 1990.

The regression analysis also included an urbanization variable. Although GNP and the extent of urbanization were closely linked before World War II, this is clearly no longer the case and many lowerincome countries now experience very high rates of urbanization. Throughout the text the term lower income is used to describe a quite heterogeneous group of nations. In addition, the term less and more developed nation is used in this article interchangeably with lower income. In the regression analyses, the percentage of energy from each macronutrient was regressed on GNP per capita, the proportion of the population residing in urban areas that year, and an interaction term between GNP per capita and the proportion of urban residents. All variables in this regression were highly significant.

Body mass index (BMI) is the standard populationbased measure of overweight and obesity status. For adults, the cut-offs used to delineate obesity are less than 18.5 for thinness (chronic energy deficiency), 18.5 to 24.99 for normal, 25.0-29.99 for overweight grade I, 30.0-39.99 for overweight grade II, and 40.0 and above for overweight grade III $^{7}$. For this article, grades II and III are combined.

\section{Factors underlying the nutrition transition}

It is useful to consider demographics and economics, two of the propositions that affect diet and activity which are changing very rapidly.

\section{Proposition 1: Major sbifts in population growtb, age structure and spatial distribution are closely associated witb nutritional trends and dietary \\ cbange}

No attempt is made here to address all aspects of this proposition but rather to focus in some detail on one of the most powerful sets of shifts linked with demographic change - rapid urbanization. Evidence indicates a most pronounced association of urbanization with the shifts in diet and activity and body composition.

People living in urban areas consume diets distinctly different from those of their rural counterparts. City dwellers have led the movement from the pattern of famine to the pattems of receding famine and the rise of degenerative disease. Compared with rural diets, urban diets show trends toward consumption of the following:

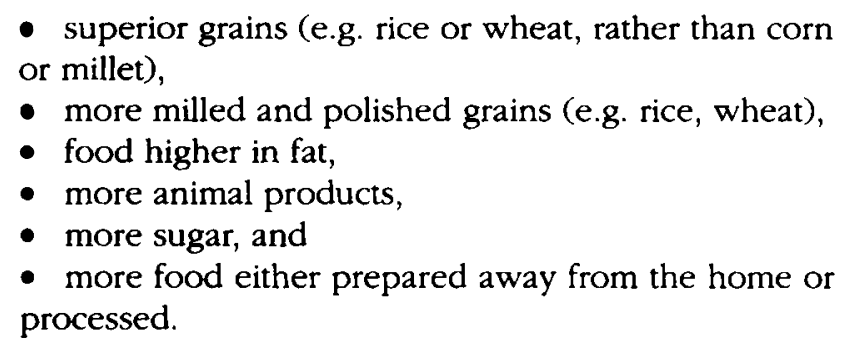

The potential impact of urbanization on diet structure is shown by this regression model. The model used FAO food balance sheets and World Bank economic indicators data for 1990 . The regression relating GNP per capita to the outcomes of energy from each food source includes as a covariate the proportion of residents residing in urban areas and an interaction between the proportion urban and GNP per capita. For the purposes of clarification of the impact of shifts in urbanization, the results of those regressions were used to predict (simulate) the diet structure with the proportion of urban residents worldwide at either 25 or $75 \%$. As shown in Figs 1 and 2, for higher rates of urbanization, the simulation developed from our model predicts a substantial increase in the consumption of sweeteners and fats. The clear implication is that a shift from 25 to $75 \%$ urban population in very low income countries would be associated with an added 4 percentage points total energy from fat and an additional 12 percentage points energy from sweeteners.

When analysis is undertaken at the country level, it is clear that these contrasts between urban and rural eating patterns are more marked in lower-income than in higher-income countries. In higher-income countries, market penetration into rural areas is common, and nationally integrated food distribution systems exist. Nevertheless, higher-income countries show important urban-rural differences in eating patterns, especially in consumption of food prepared away from home ${ }^{8}$ and responsiveness to information and the influences of mass media. Even in higher-income countries, large differences between urban and suburban food and labour markets, in combination with other factors related to residence, result in distinct dietary and nutritional status patterns.

Key factors responsible for urban-rural differences in dietary intake and resulting differences in nutritional status include:

- better transportation and marketing systems in urban areas that provide greater availability of food during periods of seasonal shortage, 


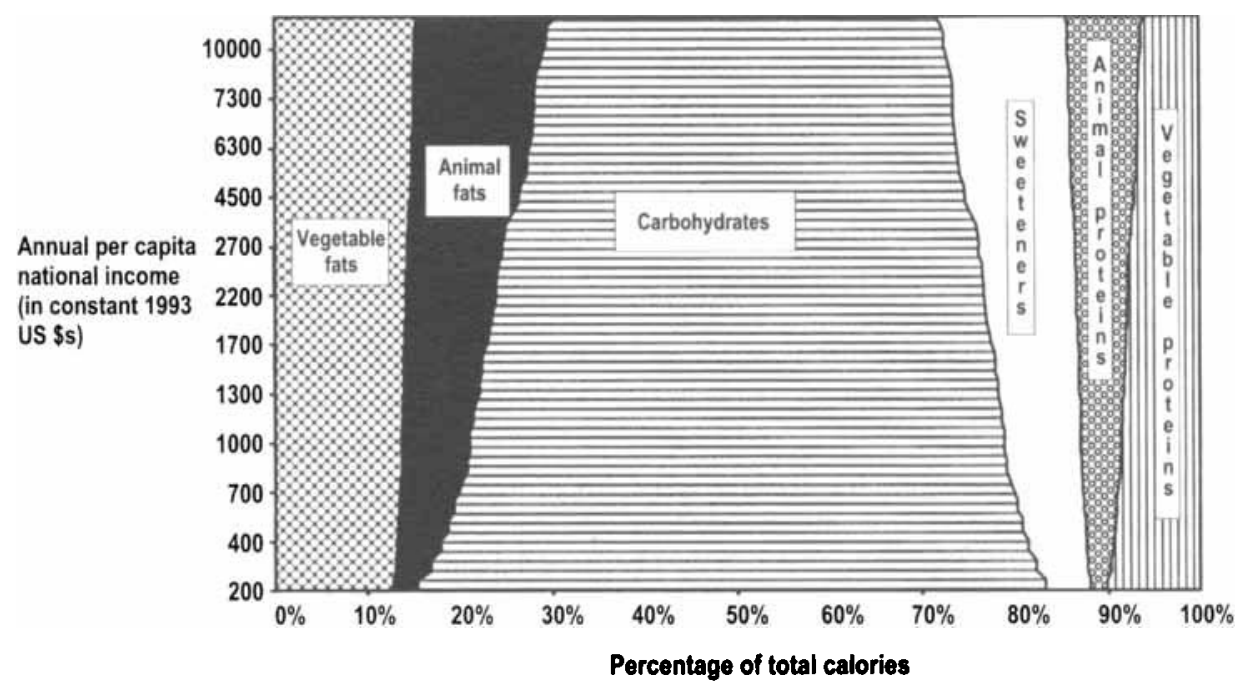

Fig. 1 Relationship between the proportion of energy from each food source and gross national product per capita with the proportion of the population residing in urban areas placed at $25 \%$, 1990. (Source: Food balance data from the FAOUN; GNP data from the World Bank; regression work by UNC-CH.)

- greater penetration of marketing activities of the processed commercial food sector into the denser urban markets,

- greater heterogeneity of urban populations with respect to dietary pattern,

- different occupational patterns, characterized in urban areas of reduced compatibility of jobs with home food preparation and child and elder care,

- different household structures related to a wide range of economic and social factors, and

- different disease and health service use patterns.

(For a more detailed review of dietary aspects of urbanization, see Popkin and Bisgrove'.)

\section{Key dimensions of world urbanization}

Several major demographic shifts began in the postWorld War II period and continue unabated and have even accelerated in some regions. One is the vast increase in the proportion of persons who reside in urban areas. A second is urban agglomeration. A third is the shift of poverty toward the urban areas, particularly toward squatter and slum areas.

\section{Proportion living in cities}

Urban growth was relatively modest before the Industrial Revolution. Rapid urban development first occurred in the higher-income countries; now, lowerincome countries are undergoing even more rapid

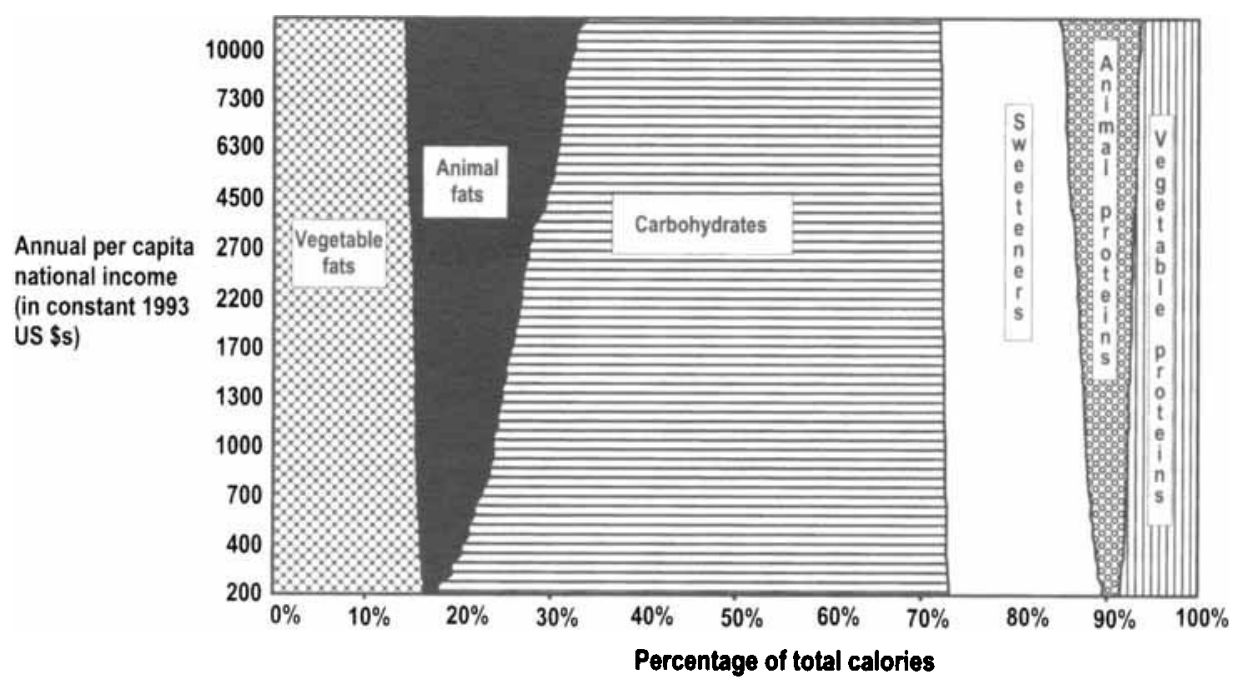

Fig. 2 Relationship between the proportion of energy from each food source and gross national product per capita with the proportion of the population residing in urban areas placed at $75 \%$, 1990. (Source: Food balance data from the FAOUN; GNP data from the World Bank; regression work by UNC-CH.) 
urbanization. In the last half of the twentieth century, urbanization resulting from migration and natural increase has become a dominant factor in all regions and shows no signs of abating. The proportion of persons living in urban areas in developed and developing countries has changed significantly since 1950. Table 1 shows that the higher-income world is comprised predominantly of urban residents today which is not the case for the less developed and poorest least developed countries ${ }^{10}$. Nevertheless, by 2025 urban residency will be the common form of residence throughout all but the poorest African countries.

The continuation of the migration of rural residents to urban areas more than offsets the much lower urban fertility rate and leads to the quite different patterns of growth in urban and rural areas. Table 2 shows that these patterns accelerate in the next century.

\section{Concentrated population growth}

Urban growth, particularly in lower-income countries, has been skewed towards a few larger cities, often called urban conglomerates. These cities of 5-27 million dominate many countries and are growing much faster in the less developed than in the more developed regions of the world. Nevertheless, in the lower-income world, more than half of the urban residents reside in smaller and medium sized cities with populations less than $500,000^{10}$. As is seen in Table 3, the most explosive growth of these mega-cities is in Asia.

\section{Shift in the proportion of poor to the cities}

Concomitant with increased concentration of the population in urban areas is a dramatic shift in the proportion of poor people living in cities. In absolute and relative terms, the majority of the poor of the lowerincome world live in cities. By the year 2000 , it is estimated that $57 \%$ of the poor will live in urban areas ${ }^{9,11}$. Estimates of the distribution of the poor are rare. The one used by the World Bank was the subject of extensive research. While it is old, it is felt to be more carefully prepared than many more current projections. However, it is estimated that a majority will reside in dense slums or makeshift dense squatter settlements. At the same time a disproportionate share of the upper income and uppermiddle income population also lives in urban areas.

Table 1 Urban population, 1970, 1994 and 2025

\begin{tabular}{|c|c|c|c|c|c|c|}
\hline \multirow[b]{2}{*}{ Region } & \multicolumn{3}{|c|}{$\begin{array}{l}\text { Urban population } \\
\text { (millions) }\end{array}$} & \multicolumn{3}{|c|}{$\begin{array}{l}\text { Urban share } \\
\text { (percentage) }\end{array}$} \\
\hline & 1970 & 1994 & 2025 & 1970 & 1994 & 2025 \\
\hline $\begin{array}{l}\text { World } \\
\text { Less developed regions } \\
\text { Least developed countries } \\
\text { More developed regions }\end{array}$ & $\begin{array}{r}1353 \\
676 \\
38 \\
677\end{array}$ & $\begin{array}{r}2521 \\
1653 \\
122 \\
868\end{array}$ & $\begin{array}{r}5065 \\
4025 \\
506 \\
1040\end{array}$ & $\begin{array}{l}36.6 \\
25.1 \\
12.6 \\
67.5\end{array}$ & $\begin{array}{l}44.8 \\
37 \\
21.9 \\
74.7\end{array}$ & $\begin{array}{l}61.1 \\
57 \\
43.5 \\
84\end{array}$ \\
\hline
\end{tabular}

Source: United Nations: Population Division, $1995^{10}$.
Table 2 Average annual growth rate of urban and rural population, less developed regions (percentage)

\begin{tabular}{lccr}
\hline Region & $1965-70$ & $1990-95$ & $2020-25$ \\
\hline $\begin{array}{l}\text { Less developed region } \\
\quad \text { urban }\end{array}$ & 3.58 & 3.51 & 2.33 \\
$\quad$ rural & 2.18 & 0.96 & -0.28 \\
Africa & & & \\
$\quad$ urban & 4.64 & 4.38 & 3.34 \\
$\quad$ rural & 1.98 & 2.03 & 0.72 \\
Asia & & & \\
$\quad$ urban & 3.28 & 3.68 & 2.31 \\
$\quad$ rural & 2.34 & 0.81 & -0.57 \\
Latin America & & & \\
$\quad$ urban & 3.97 & 2.6 & 1.26 \\
$\quad$ rural & 0.81 & -0.2 & -0.61 \\
Oceania & & & \\
$\quad$ urban & & 3.13 & 3.32 \\
$\quad$ rural & 1.26 & 1.9 & 0.22 \\
\hline
\end{tabular}

Source: United Nations: Population Division, $1995^{10}$.

\section{Migration}

An important dimension of urban growth is its associated pattern of migration. Migration from rural areas to cities (and to a lesser extent from small to larger cities) and international migration have affected diet profoundly. For example, populations of Samoans who moved to San Francisco, Polynesians and Maori who moved to New Zealand, Japanese who moved to the USA and Yemenite Jews who moved to Israel all showed large changes in diet, followed by large increases in diet-related chronic diseases ${ }^{12-15}$.

In other research, a national survey of American adolescents examines the effects of generation of birth in the USA. In this work, first-generation Americans are defined as those born outside the USA. It was found that there is more than a doubling of obesity of AsianAmerican and Hispanic adolescents between the firstgeneration and second-generation Americans (those born in the USA). With about 3400 Hispanics and over 2000 Asian-Americans in the nationally representative sample, the likelihood of being obese increased from 23.2 to $32.6 \%$ among Hispanics going from the first to second generation and 10.7 to $24.6 \%$ for AsianAmericans. The 85 th percentile reference ${ }^{7}$ was used for obesity ${ }^{16}$. As discussed below in reference to the Barker metabolic programming hypothesis ${ }^{17,18}$, it is possible that the increased obesity in these immigrants is explained partially by fetal and infant nutrition

Table 3 Mega-cities, number 1970-2015

\begin{tabular}{lcccc}
\hline Region & 1970 & 1994 & 2000 & 2015 \\
\hline World & 11 & 22 & 25 & 33 \\
Less developed region & 5 & 16 & 19 & 27 \\
$\quad$ Africa & 0 & 2 & 2 & 3 \\
$\quad$ Asia & 2 & 10 & 12 & 19 \\
Latin America & 3 & 4 & 5 & 5 \\
More developed regions & 6 & 6 & 6 & 6 \\
\hline
\end{tabular}

Note: Mega-cities have 8 or more million residents. Source: United Nations: Population Division, $1995^{\text {io }}$ 
insults: however, we feel that there is potential for an independent environmental component which may explain this American experience.

\section{Proposition 2: Cbanges in income, patterns of work and leisure activities and related socioeconomic sbifts lead to changes in women's roles and sbifts in dietary and activity patterns}

A major change in economic structure associated with the nutrition transition is the shift away from a preindustrial agrarian economy and towards increasing industrialization. This transformation then accelerates; the service sector grows rapidly, industrial production is dominated by capital-intensive processes and timeallocation patterns change dramatically. Associated socioeconomic changes especially important in the nutrition transition phenomenon are (a) changes in the role of women (especially with respect to patterns of time allocation); (b) changes in income patterns; (c) changes in household food-preparation technology; (d) changes in food production and processing technology; and (e) changes in family and household composition.

The sectoral distribution of the labour force towards industry and service has accelerated around the world. Figure 3 presents data on this pattern for higher- and lower-income countries. It shows for all lower-income countries a pronounced move away from agriculture and towards manufacturing and service employment. As has often been shown, the most labour-intensive agricultural work requires the greatest amount of energy expenditure. One of the most inexorable shifts with modernization and industrialization is the reduced use of human energy to produce more capital-intensive manufacturing and goods and services. The result is obviously a marked shift in activity patterns at work, a trend particularly associated with our shift into increasingly capital-intensive production and increasingly sedentary manufacturing, service and commercial work. This within-occupation shift in energy expenditure cannot readily be shown with national data. It requires individual level information.

Unfortunately, few longitudinal studies attempt to measure physical activity and energy expenditures. One quite simple measure of overall activity has been collected in each survey from 16,000 Chinese as part of the CHNS. Table 4 shows the shifts in the proportion of Chinese adults involved in low levels of physical activity at work. In particular, urban residents in all income groups were more likely in 1993 to have adopted a more sedentary activity pattern. Elsewhere, this is linked with significant increases in BMI and obesity $^{19}$. In contrast, this pattern was not seen in the rural areas. In fact, rural residents, particularly lowincome ones, showed a significant change from low and moderate activity patterns towards a high physical activity pattern and related to that, an increase in chronic energy deficiency measured by a BMI below 18.5 .

Related to the effect of industrialization and modernization on market production is a similar shift in time allocation and physical effort in home and leisure activities. Since the discovery of fire, a key thrust in the continuing development of household technology for processing and storing food has been to save time and enhance the quality of life. In the last century, the evolution of household technology seems to have accelerated. In food-preparation technology, recent developments include efficient ways to prepare and store food (canning, refrigeration, freezing, radiation treatment, packaging, etc.); food processing with tools such as electric mixers and food processors; and cooking with pressure cookers, cookware made with improved metals and alloys, metal stoves using various fossil fuels, and microwave ovens.

These food-preparation technologies, together with home electrification, washing machines and clothes dryers, vacuum cleaners, piped water, and so forth,

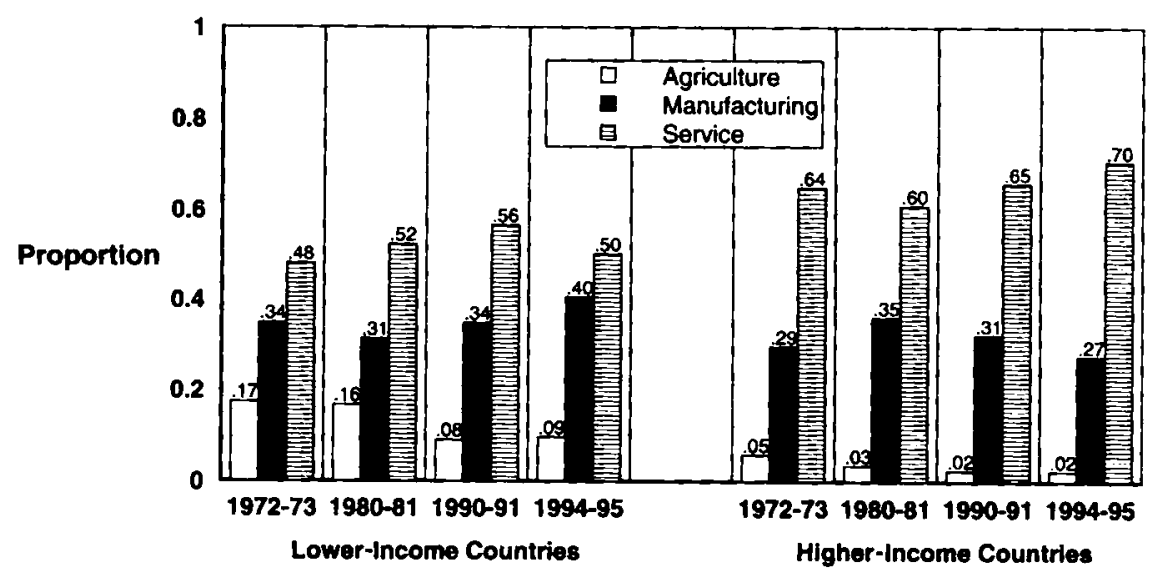

Fig. 3 Shifts in the distribition of occupation, 1972-95. (Source: World Bank, 53 countries, over a 23-year period.) 
Table 4 Distribution of physical activity of Chinese aged 20-45 years, by thirds of household income and residence, CHNS 1989, 1991 and 1993

\begin{tabular}{|c|c|c|c|c|c|c|c|c|c|}
\hline & \multicolumn{9}{|c|}{ Household income per capita thirds } \\
\hline & \multicolumn{3}{|c|}{ Low } & \multicolumn{3}{|c|}{ Middle } & \multicolumn{3}{|c|}{ High } \\
\hline & 1989 & 1991 & 1993 & 1989 & 1991 & 1993 & 1989 & 1991 & 1993 \\
\hline \multicolumn{10}{|l|}{ Urban residence } \\
\hline $\begin{array}{l}\text { lowest level activity } \\
\text { middle level activity } \\
\text { highest level activity } \\
\text { Rural residence }\end{array}$ & $\begin{array}{l}23.7^{b} \ldots \\
49.6^{b} \\
26.7^{b}\end{array}$ & $\begin{array}{l}34.3^{b} \\
30.1 \\
35.6^{b, *}\end{array}$ & $\begin{array}{l}42.6 \\
30.2 \\
27.2\end{array}$ & $\begin{array}{l}35.5^{*} \\
46.1^{\star} \\
18.4\end{array}$ & $\begin{array}{l}45.4 \\
39.7^{a} \\
14.9\end{array}$ & $\begin{array}{l}42.8 \\
40.6 \\
16.6\end{array}$ & $\begin{array}{c}44.5^{*} \\
48.0^{*} \\
7.5\end{array}$ & $\begin{array}{r}58.3 \\
34.5 \\
7.2\end{array}$ & $\begin{array}{l}55.5^{a} \\
32.0^{a} \\
12.5^{a}\end{array}$ \\
\hline $\begin{array}{l}\text { lowest level activity (\%) } \\
\text { middle level activity (\%) } \\
\text { highest level activity (\%) }\end{array}$ & $\begin{array}{l}15.3^{\star} \\
22.2^{b, \star \star} \\
62.5^{b, * \star}\end{array}$ & $\begin{array}{r}3.9^{b} \\
5.3^{b} \\
90.8^{b}\end{array}$ & $\begin{array}{r}4.8^{b} \\
7.9^{b} \\
87.3^{b}\end{array}$ & $\begin{array}{l}16.2^{*} \\
28.9^{*} \\
54.9^{*}\end{array}$ & $\begin{array}{l}12.3 \\
14.1 \\
73.6\end{array}$ & $\begin{array}{l}12.6 \\
13.3 \\
74.1\end{array}$ & $\begin{array}{l}23.7^{\mathrm{a}} \\
35.2^{*} \\
41.1^{\star}\end{array}$ & $\begin{array}{l}24.8 \\
24 \\
51.2\end{array}$ & $\begin{array}{l}19.8 \\
26.8^{\star} \\
53.4\end{array}$ \\
\hline
\end{tabular}

The proportion differs significantly from middle- and high-income groups within same year $(P<0.05)$.

The proportion differs significantly among three income groups within same year $(P<0.05)$.

-The proportion differs significantly from corresponding value in other 2 years $(P<0.05)$.

*The proportion differs significantly from corresponding value among the 3 years $(P<0.05)$.

have transformed home production from a timeconsuming, often back-breaking, full-time occupation for peasant or working-class women. Although home production still requires time and energy, purchased technology where accessible can help save time for those who engage in home production activities. One way to see how these household technologies have made transformations in a society is to examine the studies of the introduction of electricity to agricultural societies, which show large, rapid transitions in the use of time, the roles of various household members and other social factors ${ }^{20}$. Herrin's classic study on the impact of electrification on the lives of families in poorer regions has demonstrated the profound shift in the use of time related to the use of electricity.

Possibly an even more astounding shift has come in leisure activities. In the past, leisure activities for children often meant active play, but leisure today may mean a quite sedentary activity such as watching television or playing a computer game. Documentation of such patterns across the lower-income world is not available in terms of time spent and the shift in activities. This area needs greater focus.

\section{Income patterns}

Income is an important element in the nutrition transition because it measures control over the flow of goods and services. In other words, income allows one to purchase goods or services that can affect diet and activity, and nutritional status. Three key issues relating income to nutrition are (a) the effect of income changes on dietary structure; (b) the effect of income changes on the amount of energy, protein and fat consumed; and (c) the effect of change in the structure of the economy, particularly the change to commercial agriculture on the nutritional status and diet of subsistence agriculturalists. The effect of income in purchasing the assets and technologies that in turn affect time use, diet and activity patterns noted above, is equally important but not discussed here.
As Figs 1 and 2 show, increasing income is strongly associated with changes in the proportion of energy in the diet from various sources. What has been shown more recently, however, is that the strength of the income and dietary fat relationships have been somewhat uncoupled at the national level. Figure 4 presents a regression of the proportion of total, vegetable and animal fat on GNP. The results show a strong flattening of the relationship and a shift towards much higher consumption of dietary fat among poor nations than was previously known. In other words, lower-income countries are now able to afford the types of higher-fat diets that previously were accessible only to middleincome countries.

These relationships between income and diet noted in Figs 2 and 3 have an important culture-specific component. The responsiveness of dietary total energy, total and saturated fat, and other macro- and micronutrients to income change depends upon the nature of the demand for particular foods and by overall eating patterns. For example, in the Philippines, the coconut palm is a major source of cooking oil, and income increases are associated with increased away-fromhome consumption of foods that are frequently fried; thus, saturated fat and total fat consumption are highly responsive to income increases, particularly those accruing to women ${ }^{21,22}$. Similarly, in China, pork consumption is highly responsive to increases in income, which thus result in large increases in the proportion of energy from $\mathrm{fat}^{5,23,24}$. In contrast, where income increases are spent on more elaborate packaging and processing or higher quality of specific foods, rather than larger quantities of food or shifts in the types of foods, changes in income will have less effect on dietary structure.

A related point is that while the GNP-fat intake relationship has flattened, it is shown elsewhere that there remain in all countries important relationships between income and fat consumption at the individual and household level ${ }^{25}$. 


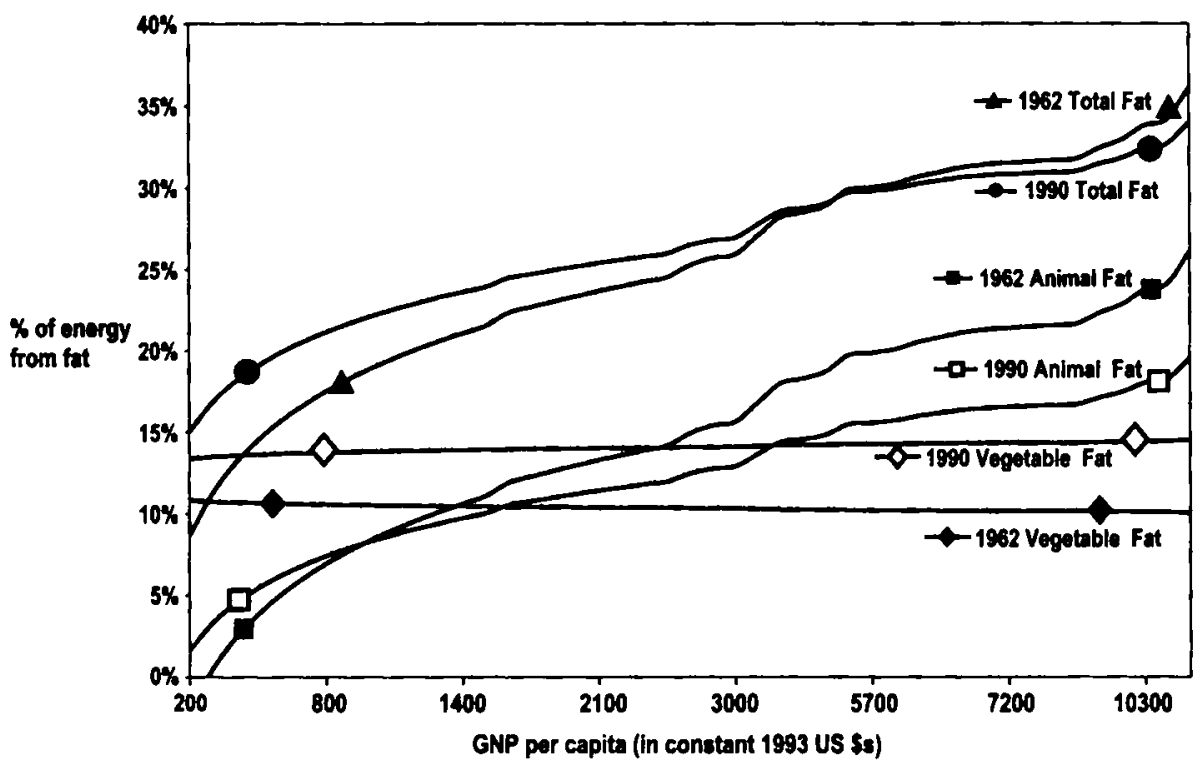

Fig. 4 Relationship between the percentage of energy from fat and GNP per capita, 1962 and 1990. (Source: Regressions run with food balance data from FAOUN and GNP data from the World Bank.)

A second apparent relationship between income and diet is that as income increases (beyond the point where total food energy needs are met), people spend more per food item ${ }^{26}$, partly to obtain higher quality. As many authors have shown, food demand is much more price- and income-elastic among the poor than among higher-income groups ${ }^{26,27}$. Changes in diet with increased income also relate to the reduced time needed to consume higher quality and higher priced goods that have undergone more processing before purchase $^{28}$

Income has been and will continue to be an important identifier of groups at risk of either nutritional deficiency or nutritional excess. Income and more complex measures of socioeconomic status that incorporate other dimensions of social and economic well-being, such as education, asset ownership, occupation and various more qualitative measures of 'status', are useful in identifying problems of deficit in all societies and problems of excess associated with the pattern of degenerative disease.

For lower-income countries, a crucial dimension of the relationship between socioeconomic status and nutrition is the distribution of chronic disease risk factors by income group. In higher-income countries, the poor are far more likely to suffer from obesity, NIDDM, chronic heart disease (CHD), and other chronic diseases ${ }^{29,30}$. This has not been found in lower-income countries, although this pattern is slowly changing. For instance, a recent World Bank study on adult health in Brazil ${ }^{31}$ indicates that where income constraints among the poor are not too severe, many risk factors for cardiovascular disease will likely be greater among the poor than among the rich. This inverse income-obesity relationship is beginning to be found in larger subpopulation groups in Brazil ${ }^{2}$ and in other Latin American countries ${ }^{32}$. Within the next 1020 years, in most of Latin America and many parts of Asia, obesity and NIDDM will become problems of poverty. There are already indications that this is occurring in South Africa ${ }^{33}$. The rapid increases in obesity found in lower-income countries are discussed below together with the consequences of this change.

\section{Intermediate factors: diet and physical activity}

While nutrition researchers have typically focused on the study of diet, it is no longer the only issue of concern. Diet and physical activity are intertwined, and interactions between energy intakes and expenditures are amenable to intervention. It may very well be that the rapid reduction in physical activity rather than diet explains as much or more of the increased obesity facing lower and transitional income countries. Research is needed to quantify the relative impact of each set of factors.

\section{Pbysical activity}

As noted above, the remarkable shifts in occupations and in travel to work along with changes in the nature of home production and leisure activity have had profound effects on activity patterns throughout the world. Few studies have measured this shift in activity and energy expenditures. One quite simple measure of overall activity has been collected in each survey from 16,000 Chinese as part of the CHNS. It has been reported elsewhere that a remarkable shift in activity patterns for adult Chinese occurred between 1989 and 1993 as shown in Table $4^{2}$. 


\section{Structure of diet}

Most researchers have focused on the shift from diets high in complex carbohydrates and fibre to those with a higher proportion of fats, saturated fats and sweeteners. But underlying these broad patterns are major shifts in the type of staples selected, and in the overall diversity of the diet. In most countries one of the first shifts is from lower quality or inferior staples to those deemed to be of higher quality. In one country lower quality might be millet, in another it might be sorghum or cassava. This shift is accompanied or followed rapidly by the decline in the proportion of energy from these basic staples.

The work undertaken to date on this nutrition transition seems to show remarkable congruity in the broad shifts in diet and in the ever-increasing shift towards higher-fat diets in all regions of the world. Little has been done systematically to lay out the role of the array of socioeconomic, technological and other factors that explain this shift. The best work has been done on the role of urban residence (e.g. the work of Bourne $e t$ $a l^{34,35}$ ) and its relationship to eating habits.

The shifts in the proportion of energy from fat, protein and carbohydrates provide some sense of the broader shift. At the country and individual level, studies have been conducted in China ${ }^{5}$ and $\mathrm{Brazil}^{36}$ to provide examples and present information from a selected set of food groups from China to highlight the food shifts. As shown in Table 5, there is a marked shift away from grains and tubers towards fats, meat and eggs amongst other things. In addition, there are marked differences in the diets of lower-, middle- and higher-income thirds in this country with a much smaller income distribution than is found in many countries. Table 5(a) presents the average intake for each food for low-, middle- and upper-income adults in 1989 and then presents the change for these adults over a 4-year period. Table 5(b) presents the proportion who consume each of these foods and the shift in the proportion (percentage points) who consumed them between 1989 and 1993. Essentially this table shows that lower-income adults consume more carbohydrates and vegetables and less meat, eggs and oils. Moreover, over time there is a pronounced trend towards a reduced consumption of grains, tubers and corn products, and an increase in consumption of meat and meat products, eggs and oils.

Table 5(b) shows that while per capita intake is changing markedly towards higher intake of fats, eggs and meats, a greater proportion of individuals is consuming many grain and vegetable products. In this table, a food grouping system is used that was developed to separate the Chinese food composition table into 33 distinct food groups. Then the number consumed by each person is added up to present mean intake and the proportion with high and low numbers of food groups consumed. It is noteworthy that there is a marked increase in diversity of the Chinese diet, but the total amount consumed of many starchy staples and other higher fibre and nutrient-rich plant-based foods is being rapidly reduced.

It is essential not to ignore the benefits of this shift. The new Chinese diet is more diverse and linked to reduced undernutrition. This trend towards a more diverse diet is seen systematically in most countries in Asia, Africa and Latin America. The diet of grains and tubers mixed with small amounts of condiments, possibly a few legumes and a small amount of meat/fish/poultry is clearly not the diet desired by the population. Using our China-UNC-CH food grouping system of 40 groups, with alcohol and condiments removed, the shift towards a more diverse diet is seen by examining the move from a very low diversity to a highly diversified diet in Table 6. Over time, the proportion of Chinese of all income groups who consume very few food groups (five was selected) has declined while those who consume more than 10 increases.

\section{Body composition}

One consequence of this nutrition transition has been a decline in undernutrition accompanied with a most rapid increase in obesity. In all age groups, there is evidence of a rapid increase in obesity and also an array of dietary excess and body composition-related health outcomes such as glucose intolerance and diabetes. Monteiro et al. ${ }^{36,37}$ (also Monteiro, forthcoming ${ }^{38}$ ) has documented this shift away from undernutrition most clearly for Brazil.

\section{Programming - a potential link}

David Barker and colleagues at the University of Southampton ${ }^{17,18}$ have brought into the mainstream the notion of metabolic programming: that early insults operating at a critical period in development result in long-term changes in the structure or function of an organism. In the case of obesity, the hypothesis is that fetal growth retardation results in metabolic changes that are adaptive under nutritionally stressful circumstances in utero. A similar argument can be made for postnatal growth retardation manifested as stunting. As the child grows, the metabolic efficiencies that served well in conditions of undernutrition become maladaptive with overnutrition, leading to the development of abnormal lipid profiles, altered glucose and insulin metabolism, and obesity.

One reason why the programming hypothesis is so powerful for health relates to its effects on the distribution of obesity. There appears to be the potential for increased visceral adiposity. That is, the literature that has linked metabolic programming with obesity has also shown a greater likelihood of 
Table 5(a) Changes in Chinese food consumption categorized by income group

\begin{tabular}{|c|c|c|c|c|c|c|}
\hline & \multicolumn{2}{|c|}{ Bottom third } & \multicolumn{2}{|c|}{ Middle third } & \multicolumn{2}{|c|}{ High third } \\
\hline & $\begin{array}{c}1989 \\
\text { (g/capita/day) }\end{array}$ & $\begin{array}{l}\text { Change from } \\
1989 \text { to } 1993\end{array}$ & $\begin{array}{c}1989 \\
\text { (g/capita/day) }\end{array}$ & $\begin{array}{l}\text { Change from } \\
1989 \text { to } 1993\end{array}$ & $\begin{array}{c}1989 \\
\text { (g/capita/day) }\end{array}$ & $\begin{array}{l}\text { Change from } \\
1989 \text { to } 1993\end{array}$ \\
\hline Whole steamed/boiled rice & 317.0 & -40.4 & 322.2 & -10.6 & 287.3 & -10.3 \\
\hline Wheat flour & 176.2 & 5.6 & 145.4 & -39.7 & 151.2 & -72.5 \\
\hline Fresh and dried com & 69.4 & -38.4 & 28.0 & -9.8 & 20.4 & -10.3 \\
\hline Coarse grains & 29.7 & -14.7 & 10.6 & -2.9 & 6.6 & 2.2 \\
\hline Legumes & 12.7 & -1.3 & 10.9 & -2.5 & 12.1 & -2.2 \\
\hline Tofu & 23.0 & -3.2 & 28.5 & -6.0 & 23.7 & 1.3 \\
\hline Tofu products & 11.7 & -1.2 & 13.1 & 1.3 & 16.9 & -0.6 \\
\hline Starchy roots & 133.0 & -77.5 & 63.0 & -27.4 & 41.8 & -13.6 \\
\hline Carotene-rich vegetables & 78.8 & -2.6 & 82.6 & 9.9 & 73.4 & 12.7 \\
\hline Other vegetables & 318.7 & -55.6 & 264.4 & -1.9 & 230.3 & 7.7 \\
\hline Low-fat red meat/dishes & 3.8 & 2.2 & 6.1 & 5.2 & 8.9 & 10.2 \\
\hline High-fat red meat/dishes & 29.1 & 2.0 & 44.6 & 5.3 & 53.8 & 17.1 \\
\hline Poultry and game & 4.2 & -0.6 & 6.4 & 3.0 & 7.9 & 4.6 \\
\hline Meat products & 2.2 & -0.7 & 2.1 & 0.7 & 3.4 & -0.1 \\
\hline Organ meats & 2.2 & -0.2 & 3.3 & 0.5 & 4.3 & 0.2 \\
\hline Eggs and egg products & 7.1 & 2.8 & 9.2 & 6.0 & 16.3 & 4.2 \\
\hline Plant oils & 12.9 & 12.6 & 15.5 & 16.1 & 17.3 & 19.2 \\
\hline
\end{tabular}

increased waist-hip ratio and other measures of visceral or abdominal obesity. A separate literature has demonstrated that increased visceral adiposity is linked with NIDDM, CHD and stroke ${ }^{39}$.

In other work, four nationally representative samples of children (or a nationwide one for China) show that indeed there is potential that this hypothesis represents a critical link between the fetal and infant insults associated with underdevelopment and the transition towards a lower activity/higher-fat diet associated with the nutrition transition ${ }^{40}$. In fact, without this transition in diet and activity it would not be possible for the biological effects associated with metabolic programming to lead to abnormal lipid profiles or obesity.

The high level of child obesity in China, Russia and South Africa in comparison with National Health and Nutritional Examination Survey (NHANES) III is discussed elsewhere ${ }^{40}$. The really solid causal work on this metabolic programming relationship and any mechanisms that might explain it or Barker's hypothesis is either in process or remains to be undertaken. If this most significant relationship, often termed the programming effect, is as important as the early descriptive results indicate, then this represents an ominous warning regarding infant health. Low-income countries with high fetal and infant malnutrition rates, must make particularly rapid programme and policy shifts to address these additional undesirable consequences of the nutrition transition ${ }^{41}$.

As issues of obesity and later NIDDM are presented below, it is important for the reader to be aware of this hypothesis and its potential for explaining, among other issues, the higher NIDDM levels found in newer urban residents in black South Africa and the parts of

Table 5(b) Changes in the proportion of Chinese consuming each food group categorized by income group

\begin{tabular}{|c|c|c|c|c|c|c|}
\hline & \multicolumn{2}{|c|}{ Bottom third } & \multicolumn{2}{|c|}{ Middle third } & \multicolumn{2}{|c|}{ High third } \\
\hline & $\begin{array}{c}1989 \\
\text { (\% consuming) }\end{array}$ & $\begin{array}{c}\text { Change in } \% \text { from } \\
1989 \text { to } 1993\end{array}$ & $\begin{array}{c}1989 \\
(\% \text { consuming })\end{array}$ & $\begin{array}{c}\text { Change in \% from } \\
1989 \text { to } 1993\end{array}$ & $\begin{array}{c}1989 \\
\text { (\% consuming) }\end{array}$ & $\begin{array}{c}\text { Change in \% from } \\
1989 \text { to } 1993\end{array}$ \\
\hline Whole steamed/boiled rice & 72.4 & 1.3 & 84.3 & 2.5 & 90.7 & 0.9 \\
\hline Wheat flour & 45.7 & -0.8 & 57.5 & -18.4 & 67.6 & -30.2 \\
\hline Fresh and dried corn & 31.2 & -9.5 & 17.6 & -3.1 & 16.1 & -5.3 \\
\hline Coarse grains & 12.9 & -2.7 & 9.7 & -1.0 & 9.4 & 1.2 \\
\hline Legumes & 18.9 & -3.6 & 18.7 & -3.9 & 19.6 & -4.9 \\
\hline Tofu & 25.5 & 1.1 & 34.1 & -0.0 & 33.3 & 3.3 \\
\hline Tofu products & 22.0 & 2.1 & 28.0 & 3.3 & 35.7 & 0.4 \\
\hline Starchy roots & 38.6 & -0.5 & 34.6 & -1.8 & 32.7 & $-\mathbf{3 . 0}$ \\
\hline Carotene-rich vegetables & 42.4 & 6.0 & 56.1 & 3.9 & 60.3 & 8.9 \\
\hline Other vegetables & 92.3 & 4.0 & 92.7 & 3.2 & 95.7 & 1.2 \\
\hline Low-fat red meat/dishes & 6.6 & 2.5 & 13.2 & 3.9 & 18.6 & 8.5 \\
\hline High-fat red meat/dishes & 36.8 & 7.0 & 57.5 & 3.5 & 69.1 & 6.7 \\
\hline Poultry and game & 5.8 & 0.8 & 10.0 & 3.8 & 14.1 & 5.8 \\
\hline Meat products & 3.8 & -0.0 & 4.3 & 1.1 & 6.9 & -0.3 \\
\hline Organ meats & 4.4 & -0.4 & 7.7 & 1.4 & 11.0 & 0.4 \\
\hline Eggs and egg products & 14.9 & 7.8 & 24.5 & 10.1 & 40.9 & 3.7 \\
\hline Plant oils & 56.6 & 30.6 & 63.3 & 24.3 & 69.7 & 19.7 \\
\hline
\end{tabular}


Table 6 Diversity in the Chinese diet: the number of food groups consumed by Chinese adults aged 20-45 years, CHNS 1989-93

\begin{tabular}{lcccc}
\hline & \multicolumn{3}{c}{ Income thirds } & \\
\cline { 2 - 4 } Year & Low & Medium & High & Total \\
\hline 1989 Sample size & 1892 & 1889 & 1834 & 5615 \\
Mean score & 6.5 & 7.7 & 9 & 7.7 \\
Score <5 (\%) & 17.1 & 6.8 & 3.5 & 9.2 \\
Score > 10 (\%) & 4.4 & 12.1 & 29.6 & 15.2 \\
1991 Sample size & 1855 & 1918 & 1839 & 5612 \\
Mean score & 7.4 & 8.1 & 9.6 & 8.2 \\
Score <5 (\%) & 10.7 & 6.6 & 1.8 & 6.4 \\
Score > 10 (\%) & 5.9 & 17.8 & 35.2 & 19.5 \\
1993 Sample size & 1749 & 1814 & 1680 & 5243 \\
Mean score & 7.3 & 8.5 & 9.7 & 8.5 \\
Score <5 (\%) & 6.6 & 2.8 & 1.2 & 3.5 \\
Score > 10 $(\%)$ & 9 & 21.8 & 36 & 22 \\
\hline
\end{tabular}

Note: the range of diversity scores is $1-33$.

the increases in NIDDM elsewhere in Latin America, Asia and Africa.

\section{Prevalence in lower- and middle-income countries}

Limited information is presented on obesity patterns and trends in lower-income countries. The focus is on a few cases and the reader is directed to a more thorough review for more detail. Data from Asia and Latin America for adults are presented in Figs 5 and 6. We look at three measures of obesity, grade I, grades II and above, and the total of all grades. The ages for these data vary slightly but generally are presented for age 20 years and above.

\section{Latin America}

When looking at grades I and II and above obesity measures for Latin America, levels of obesity in the 30 and higher range are found in Brazil, Mexico and Cuba. The range is lower in other South American countries but there is no nationally representative survey for most countries. In Brazil and Cuba, women have higher levels of overweight and obesity than men but this is reversed in one survey in Mexico conducted in 1995. There are few data available in terms of large-scale surveys in the Caribbean; however, other studies and the Cuban data presented here indicate that the Caribbean nations have very high levels of obesity ${ }^{42}$.

\section{Asia}

There is still much less obesity in the largest two countries in Asia, China and India, but levels are higher in other countries. For instance, total grade I and above levels are between 25 and 30\% for Malaysia, and 13 and $19 \%$ for the Philippines. The exceptions are the Central Asian countries such as Kyrgyzstan that were members of the Soviet Union prior to 1992. Grade I overweight status is currently the major problem in Asia except for Malaysia. There is no clear gender pattern to levels of obesity in Asia.

\section{Trends}

There are a small number of lower-and middle-income countries for which we have excellent data on trends in body composition. Nationally representative or large nationwide data sets are available for Brazil in Latin America; China and India in Asia; Mauritius in Africa; Nauru and Western Samoa in the South Pacific; and Russia. These provide some sense of trends in adult obesity. Figure 7 shows the trends for the few countries for which there are nationally representative data. We created 10-year changes in the percentage points of obesity for each. Much greater detail of these obesity patterns and trends are presented elsewhere ${ }^{43}$.

\section{Brazil}

Monteiro and his colleagues ${ }^{36}$ have shown that during a 15-year period, the proportion of grade II and above overweight adult males almost doubled (5.7 to $9.6 \%$ )

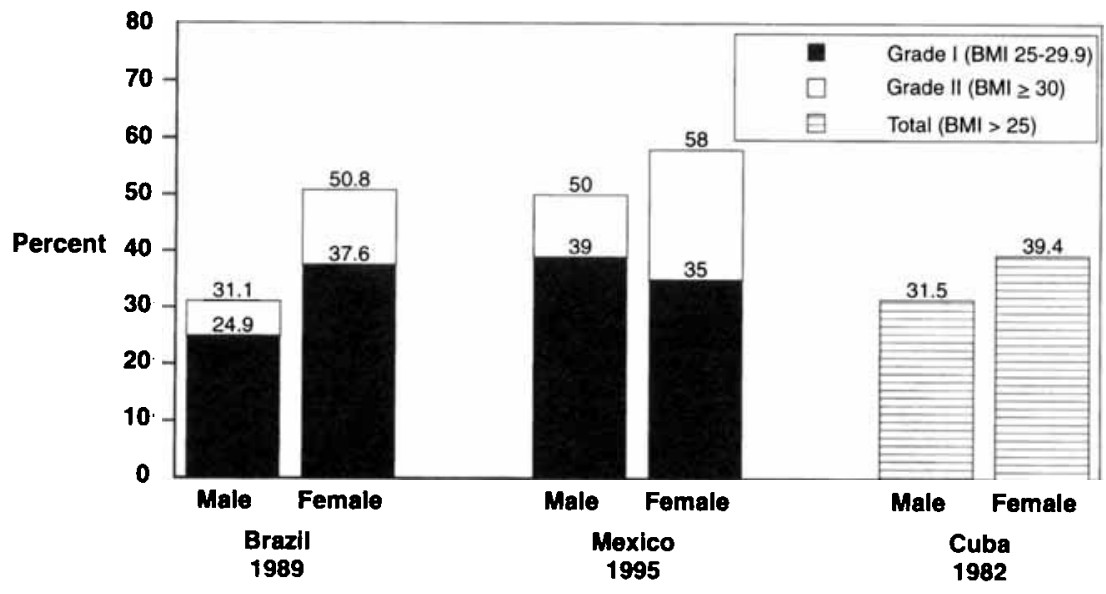

Fig. 5 Obesity patterns in Latin America 


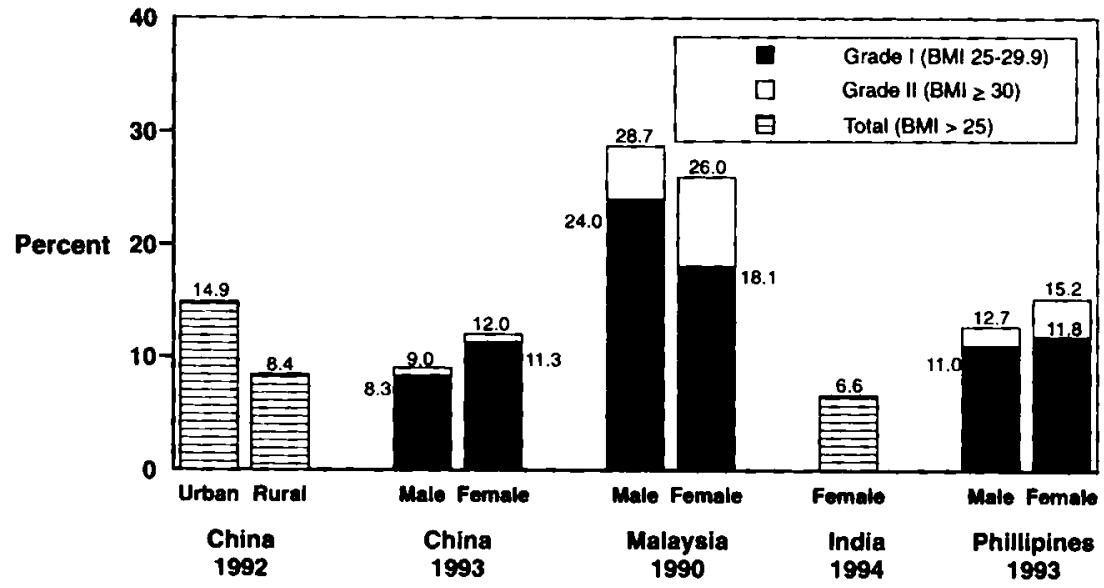

Fig. 6 Obesity patterns in Asia

For females of reproductive age the proportion of grade II obesity increased by $230 \%$ over a 21 -year period. Interestingly, it was shown that the ratio between the underweight and overweight prevalence, a measure of the relative importance of each problem in the population, was dramatically affected between 1974 and 1989. In the case of all adults, the ratio was even reversed: in 1974, underweight exceeded overweight by 1.5 times while in 1989 those overweight exceeded the underweight by more than twice. These increases in the frequency of overweight occur for all incomes and both sexes, but they tend to be far more important among the poorest families ${ }^{36}$.

\section{Cbina}

The shifts in diet, physical activity and overweight status in China are among the most rapid ever documented. The level of overweight status in China among adults is still low but the marked shifts in diet and activity and grade I overweight lead one to believe that major increases in grades I and Il overweight will occur. These changes are much greater among urban residents of all income backgrounds and among middle- and higher-income rural residents ${ }^{19}$. In China we are able to explore the trends by income group for the 1989-93 period and have found that the rate of increase among the urban and rural lowest income third is the greatest.

The rates of increase based on national nutrition surveys in China in 1982-92 indicate a moderate rate of increase; however, this hides the more rapid shifts in diet, activity and obesity seen in the last few years ${ }^{44}$. The increase in the prevalence of 5.2 percentage points of grade I overweight during this 10-year period in urban areas is considerable. During the more recent period, the CHNS data for 1989-93 show that there has been a consistent increase in obesity in urban and rural areas among adults. The CHNS 1989 survey results for this age group fit exactly in the middle of these results. Grade I and above obesity increased from $9.7 \%$ in 1982 to $14.9 \%$ between 1982 and 1993 .

\section{India}

Unlike China, far fewer data are available for India. Information is available only for women of child-

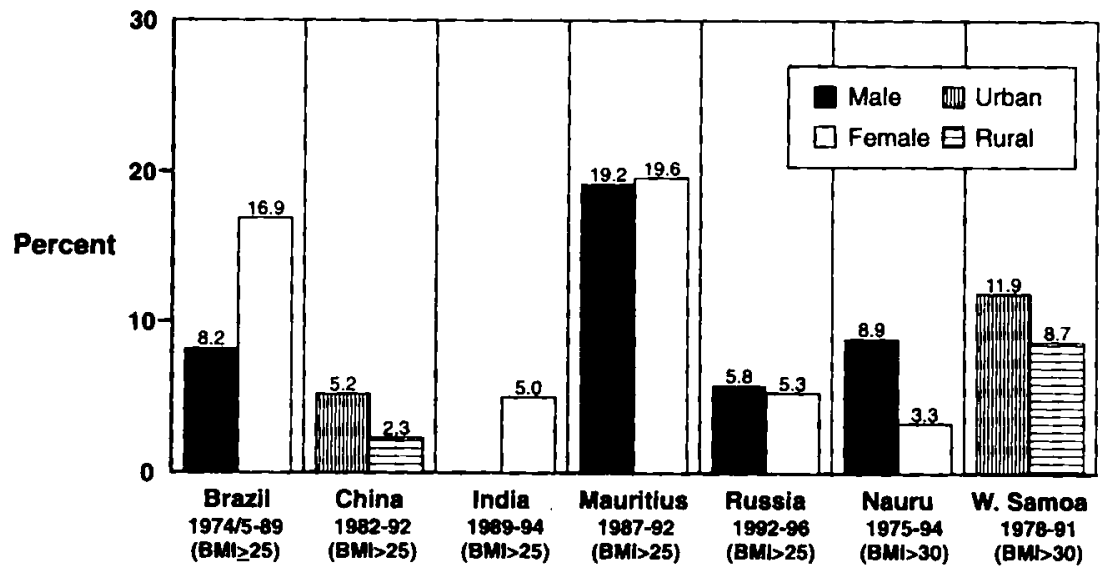

Fig. 7 Obesity trends: the percentage point increase in obesity prevalence per 10-year period 
bearing age which indicates a small increase over the 19 years but a more rapid increase of 4.2 percentage points during the 1989-94 period.

\section{Russia}

Russia has one of the highest rates of mortality related to CHD in the world. Despite shifts towards a lower-fat diet in the post-reform period, there is evidence of an increase in adult obesity. Data have been collected for seven rounds of the nationally representative Russian Longitudinal Monitoring Survey and there is over time a consistent increase in adult and also elderly obesity ${ }^{43}$. Figure 8 presents information on trends in body composition in Russia. The remarkable point to note is that the effects of the economic hardship in Russia have not been seen in the obesity trends. In 1996 the grade II obesity of females showed a decline. A much higher rate of increase in prevalence of obesity was found among grade II and above obesity for Russian females. Overall, the increase in total obesity is over 5 percentage points per 10-year period for Russia but future directions of this trend are less clear because the economy is in such flux.

\section{The health implications: NIDDM and related conditions}

A range of changes in health are accompanying the nutrition transition. As noted above, foremost is the reduction of infant mortality - and related to that is undernutrition. Wasting is being rapidly reduced in many countries and rates of stunting are also being lowered though recent information indicates that the rate of change has slowed considerably in the last few years ${ }^{45}$. At the same time, many adverse changes are taking place. The positive effects are not addressed here - effects that must not be lost nor minimized. Rather the focus is on the other side of the coin - the negative health effects which represent the most lasting and costly side effect of the nutrition transition.
There is a growing literature that documents rapid increases in NIDDM in many lower-income countries $^{33,46,47}$. Other work indicates that many of the cardiovascular conditions related to NIDDM such as hypertension, dyslipidaemia and atherosclerosis are documented as increasing rapidly. The epidemiological prevalence data are spotty but indicate serious and high levels of these conditions, in particular NIDDM. NIDDM comprises $85 \%$ or more of all diabetes cases. Recently, a most provocative cancer study has laid a strong basis for linking the diet, activity and body composition trends discussed above to the likelihood of increased rates of prevalence for a larger number of cancers $^{48}$.

A related clinical and epidemiological literature highlights the importance of the same factors noted as being central to the nutrition transition - diet shifts, reduced physical activity and obesity - as also being critical determinants of NIDDM $^{49-52}$. More recently this same literature has clarified the potential role for genetics and regional adiposity as they interact with these other factors.

Diet is the least understood determinant of NIDDM. A clear literature has shown that in terms of mechanisms and epidemiology, obesity and activity are closely linked to NIDDM. Several reviews lay out the case for these factors. Zimmet and his colleagues have been particularly earnest in exploring these issues at the population level in a number of lower-income and transitional societies ${ }^{51,52}$.

Some basic characteristics of NIDDM may provide a clear basis for linking key components of the nutrition transition - increases in obesity and reductions in activity - to the rapid increases in NIDDM in lowerincome countries.

\section{Obesity}

It is clear that obesity, and more particularly upperbody regional distribution of the body fat, is a key parameter in the aetiology of NIDDM. A vast literature

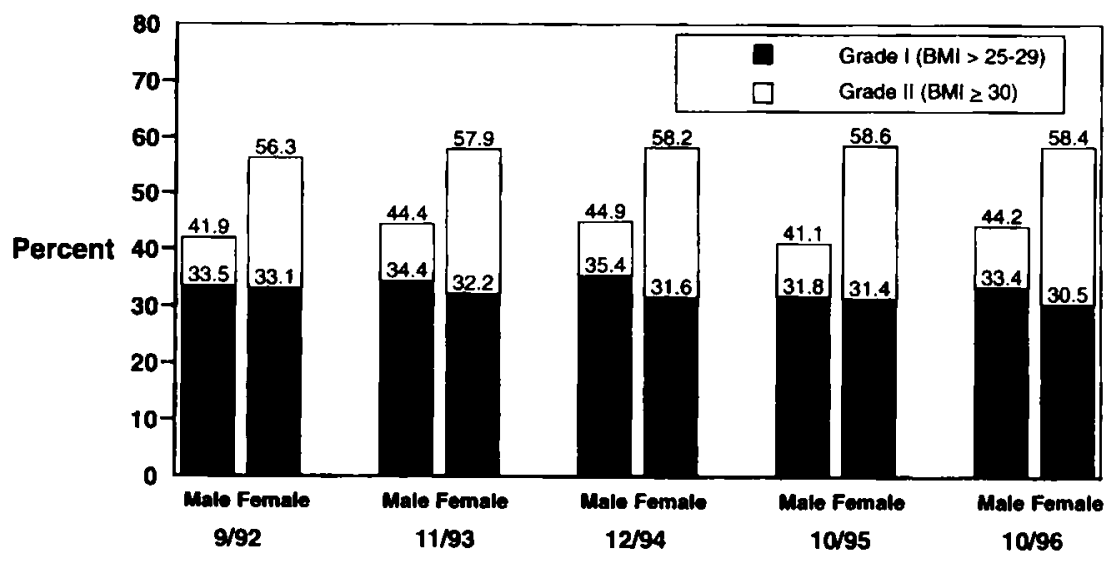

Fig. 8 Obesity trends in Russia, 1992-96 
has shown significant direct obesity relationships with NIDDM and the animal literature backs up this relationship. The work on abdominal obesity and its effects is more recent, but appears to be promising in more precisely explaining the role that body composition plays. To the extent this abdominal obesity relationship holds, the metabolic programming hypothesis becomes that much more important in showing a link between fetal and infant nutritional insults and their relationship to adiposity in the upper body area. Law et al. (see Barker ${ }^{17}$ ), in a follow-up study of British men, found abdominal fatness in adults to be associated with reduced fetal growth, manifested by low birth weight (LBW), and in particular LBW relative to placental weight. In a study of American white people and Hispanics, Valdez et al. ${ }^{53}$ found that the odds of expressing a syndrome consisting of dyslipidaemia, hypertension, unfavourable fat distribution and NIDDM were 1.72 times higher for the lowest compared to the middle third of birth weight.

In addition, there is a strong relative risk linking weight increases with diabetes. The odds of getting diabetes are considerable with a weight gain of $5-8 \mathrm{~kg}$ for adults and they increase as weight gain goes up ${ }^{54}$.

\section{Pbysical activity}

It is understood that exercise affects insulin sensitivity such that heavy activity reduces the likelihood for a given level of obesity that a person will display the signs that allow him/her to be categorized as having NIDDM. In other words, physical activity lowers the serum insulin level or appears to do so. Zimmet reviews these relationships and notes other critical studies on this topic ${ }^{51,52}$.

\section{Interactions of obesity and activity}

Activity and obesity appear to interact but also to have separate effects. For example studies show that for each level of BMI or waist-hip ratio, there is an activity effect in terms of serum insulin level.

\section{Genetic component}

Zimmet and others who have focused on this issue as it relates to lower-income countries have felt that the highest genetic susceptibility was for Pacific Islanders, American-Indians, Mexican-Americans and other Hispanics, and Asian-Indians. Those with modest genetic susceptibility include Africans, Japanese and Chinese ${ }^{51.52}$. The age of onset of NIDDM is much lower for these populations and for a given level of obesity and waist-hip ratio it appears that the prevalence is higher. For instance, while the diagnosis is usually made after the age of 50 years, in these populations it is made much earlier.

Some of the articles that document the obesity increase, in particular those for Mauritius and the
Pacific Islands and also for urban black South Africa also have shown a comparable rapid increase in the incidence of NIDDM and the biological precursors, higher glucose intolerance ${ }^{33,46,47}$.

O'Dea and colleagues 55 and also Galanis and colleagues $^{56}$ have explored the same issues in depth among Australian Aborigines and other South Pacific groups and have provided careful documentation of this linkage of the transition with NIDDM.

Evidence from dozens of smaller studies in China, the Western Pacific, South Africa, urban areas in many other countries, and other countries point clearly to an incipient major increase in cardiovascular disease in all of these countries ${ }^{47,57-59}$.

\section{Discussion and implications}

The nutrition transition addresses a broad range of socioeconomic and demographic shifts that bring rapid changes in diet and physical activity levels to most regions of the world. The changes are occurring most rapidly as is shown by the shifts in the distribution of the population, income and occupation patterns. The diet changes, most specifically the shifts towards the higher fat and meat/reduced carbohydrate and fibre diet, is also a shift towards a more diverse and pleasurable diet. The activity patterns also represent a shift away from onerous, difficuit labour-intensive activities. Thus, these dietary and physical activity shifts are desirable in many ways. Yet they carry with them many onerous nutritional and health effects. It is this paradox and complexity which makes it most difficult to understand ways to arrest the negative aspects of the nutrition transition. It is also clear that we must view the causes of obesity as environmental rather than personal or genetic.

We must be aware of the weak database on which this work relies. Documentation at the individual and household level of this transition exists in only a few countries. These countries, such as China, indicate a marked shift away from traditional coarse grains and towards refined grains and then towards meat, eggs and fats. They also indicate a strong propensity for increased income to be linked with increased dietary diversity and increased consumption of these higher fat 'Western diets'. Similarly they show marked changes in activity and obesity. Soon they will show the even more marked increases in CHD and NIDDM as others have shown in these countries. Yet, evidence for the shifts in physical activity is mainly indirect. The few studies that have monitored these trends have linked them to increased obesity but far more is needed in the way of research on this topic. This lack of research is a major gap, as are studies that collect both diet and activity data.

There is evidence that trends in obesity are not 
limited to one region, country or racial/ethnic group. The overall levels that are found in selected countries such as Mexico, South Africa, Malaysia, and nations of the Western Pacific are indicative of major public health problems. That these changes appear to be occurring across so many countries lends weight to the need to understand the underlying environmental causes related both to shifts in diet and activity rather than focusing attention solely on genetic causes of obesity. It also opens up the possibility that international studies can help to clarify the causes for these patterns.

It is likely that the rate of increase in obesity and NIDDM will increase rapidly, if the Barker metabolic programming hypothesis is correct. Stunting levels are very high in most lower-income countries. It is not unusual for $15-35 \%$ of children to be stunted ${ }^{40}$. High rates of intrauterine growth retardation and LBW also exist. To the extent that fetal and infant insults, later combined with reduced activity and increased diet, lead to obesity and NIDDM, the African, Asian and Latin American regions might see rapid increases in the health complications associated with the nutrition transition.

The challenge is to devise ways to improve the lives of our citizens - that is to give people the more varied and tasty diets they want and less burdensome work but also to prevent obesity, NIDDM, CHD and the other major diseases of civilizations. But we have few examples of countries that have been able to tackle these issues at the national level. Elsewhere I have summarized some of these issues. Milio has studied these trends most systematically ${ }^{60-62}$. The Scandinavian countries are unique in attempting to redirect their diets and health with prevention at the national level and they have done this with mixed success. Lower-income countries are only beginning to discuss and consider options for dealing with obesity. So long as poverty and hunger affect portions of the population, at the international and national level, the public and politicians are more likely to address that problem than they are to consider obesity. This means that not only are we trying to redirect popular changes in diet and activity, but we are also attempting to fight them during a time when public attention is focused on these problems of poverty and dietary deficit. Our solutions must not adversely affect the undernourished. At the same time we must begin to develop an array of largescale options that national governments can implement. As with any other epidemic, we must focus much of our energy on environmental solutions.

\section{Acknowledgements}

Preparation of this article was supported in part by grants from the American National Institutes of Health (R01-HD30880). The author thanks Xuguang Guo for assistance with the China data, Colleen Doak for assistance with the obesity patterns, Tom Swasey for work on the graphics, Lynn Igoe for editorial assistance, and Frances Dancy for administrative assistance. Credit is also given to collaborators on the China Health and Nutrition Survey, in particular Drs Ge Keyou and Zhai Fengying, Institute of Nutrition and Food Hygiene, Chinese Academy of Preventive Medicine and on the Russian Longitudinal Monitoring Survey, Dr Alexander Baturin, Institute of Nutrition, Russian Academy of Medical Sciences.

\section{References}

1 Popkin BM. Nutritional patterns and transitions. Popul. Devel. Rev. 1993; 19: 138-57.

2 Popkin BM. The nutrition transition in low-income countries, an emerging crises. Nutr. Rev. 1994; 52: 285-98.

3 Omran AR. The epidemiologic transition, a theory of the epidemiology of population change. Milbank Mem. Fund $Q$. 1971; 49: 509-38.

4 Webster's Third New International Dictionary of the English Language Unabridged: Encyclopedia Britannica Series. Chicago: Benton \& G C Merriam, 1966.

5 Popkin BM, Ge K, Zhai F, Guo X, Ma H, Zohoori N. The nutrition transition in China: a cross-sectional analysis. Eur. J. Clin. Nutr. 1993; 47: 333-46.

6 FAOSTAT.PC. Food Balance Sheets 1961-94. Rome: Food and Agriculture Organization of the United Nations, 1996.

7 WHO Expert Committee. Physical Status: the Use and Interpretation of Antbropometry: Report of a WHO Expert Committee. WHO Technical Report Series 854. Geneva: World Health Organization, 1995.

8 Haines PS, Hungerford DW, Popkin BM, Guilkey DK. Eating patterns and energy and nutrient intakes of US women. $J$. Am. Diet. Assoc. 1992; 92: 698-704, 707.

9 Popkin BM, Bisgrove EZ. Urbanization and nutrition in lowincome countries. Food Nutr. Bull. 1988; 10: 3-23.

10 United Nations, Department for Economic and Social Information and Policy Analysis, Population Division. World Urbanization Prospects: the 1994 Revision: Estimates and Projections of Urban and Rural Populations and of Urban Agglomerations. New York: Population Division, Department for Economic and Social Information and Policy Analysis, Lnited Nations, 1995.

11 Churchill AA. Shelter, Poverty and Basic Needs Series. Washington, DC: World Bank, 1980.

12 Marmot MG, Syme SL, Kagan A, Hiroo K, Rhoads G Epidemiologic studies of $\mathrm{CHD}$ and stroke in Japanese men living in Japan, Hawaii, and California: prevalence of coronary and hypertensive heart disease and associated risk factors. Am. J. Epidemiol. 1975; 102: 514-25.

13 Prior I, Tasman-Jones C. New Zealand Maori and Pacific Polynesians. In: Trowell HC, Burkitt DP, eds. Western Diseases: Their Emergence and Prevention. Cambridge, MA: Harvard University Press, 1981.

14 Toor M, Katchalsky A, Agmon J, Allalouf D. Serum-lipid and atherosclerosis among Yemenite immigrants in Israel. Lancet 1957; i: 1270-3.

15 Worth RM, Kato H, Rhoads GG, Kagan K, Syme SL. Epidemiologic studies of coronary heart disease and stroke in Japanese men living in Japan, Hawaii and California: mortality. Am. J. Epidemiol. 1975; 102: 481-90.

16 Popkin BM, Udry JR. Adolescent obesity in the United States: the national longitudinal study of adolescent health. J. Nutr. $1998 ; 128$. 
17 Barker DJP. Fetal and Infant Origins of Adult Disease London: British Medical Journal, 1992.

18 Barker DJP. Motbers, Babies and Disease in Later Life. London: BMJ Publishing, 1994.

19 Popkin BM, Paeratakul S, Zhai F, Ge K. Dietary and environmental correlates of obesity in a population study in China. Obesity Res. 1995; 3: 135S-43S

20 Herrin AN. Rural electrification and fertility change in the Southern Philippines. Popul. Dev. Rev. 1979; 5: 61-86.

21 Bisgrove EZ. Work and income as determinants of urban Filipino women's nutrient intake from commercially prepared and home prepared food. PhD dissertation, Chapel Hill, University of North Carolina, 1991

22 Bisgrove EZ, Popkin BM. Does women's work improve their nutrition: evidence from the urban Philippines. Soc. Sci. Med. 1996; 43: 1475-88.

23 Chen CM. Dietary Guidelines for food and agriculture planning in China. In: Proceedings of International Symposium on Food Nutrition and Social Economic Development. Beijing: Chinese Academy of Preventive Medicine, 1991: 40-8.

$24 \mathrm{Ma} \mathrm{H}$, Popkin BM. Income and food consumption behavior in China: a structural shift analysis. Food Nutr. Bull. 1995; 16: 155-65.

25 Drewnowski A, Popkin BM. The nutrition transition: new trends in the global diet. Nutr. Rev. 1997; 55: 31-43.

26 Chaudri R, Timmer CP. The Impact of Changing Affluence on Diet and Demand Patterns for Agricultural Commodities. World Bank Staff Working Papers 785. Washington, DC: World Bank, 1986.

27 Timmer CP, Falcon WP, Pearson SR. Food Policy Analysis Baltimore: Johns Hopkins University Press, 1984.

28 Mincer $\mathbf{J}$. Market prices, opportunity costs, and income effects. In: Christ CF, Friedman M, Goodman LA, et al, eds. Measurement in Economics. Stanford, CA: Stanford Uni versity Press, 1963.

29 Brunner EJ, Marmot MG, White IR, et al. Gender and employment grade differences in blood cholesterol, apolipoproteins and haemostatic factors in the Whitehall II study. Atherosclerosis 1993; 102: 195-207.

30 Sobal J, Stunkard A. Socioeconomic status and obesity: a review of the literature. Psychol. Bull. 1989; 105: 260-75.

31 Briscoe, J. Brazil. The New Challenge of Adult Health. A World Bank Country Study. Washington, DC: the World Bank, 1990.

32 Duncan, BB, Schmidt MI, Achutti AC, Polanczyk CA, Benia LB, Maia AAG. Socioeconomic distribution of noncommunicable disease risk factors in urban Brazil: the case of Porto Alegre. Bull. PAHO 1993; 27: 337-49.

33 Levitt NS, Katzenellenbogen JM, Bradshaw D, Hoffman MN, Bonnici $F$. The prevalence and identification of risk factors for NIDDM in urban Africans in Cape Town, South Africa. Diabetes Care 1993; 16: 601-7.

34 Bourne LT, Langenhoven ML, Steyn K, Jooste PL, Laubscher JA, Van Der Vyver E. Nutrient intake in the urban African population of the Cape Peninsula, South Africa: the BRISK Study. Cent. Afr. Med. J. 1993; 39: 238-47.

35 Boume LT, Langenhoven ML, Steyn K, Jooste PL, Nesamvuni $\mathrm{AE}$, Laubscher JA. The food and meal pattern in the urban African population of the Cape Peninsula, South Africa: the BRISK Study. Cent. Afr. Med. J. 1994; 40: 140-8.

36 Monteiro CA, Mondini L, de Souza ALM, Popkin BM. The nutrition transition in Brazil. Eur. J. Clin. Nutr. 1995; 49: 105-13.

37 Monteiro CA, Benicio MHD'A, Iunes RF, Gouveia NC, Taddei JAAC, Cardoso MAA. Nutritional status of Brazilian children: trends from 1975 to 1989 . Bull. WHO 1992; 70: 657-66.

38 Monteiro CA. The Changing Nature of Nutritional Disorders in the Developing Countries: the Case of Brazil. Proceedings of the International Congress of Nutrition. Montseal: Canadian Federation of Biological Sciences, forthcoming.
39 Bjorntorp P. Visceral obesity: a 'civilization syndrome'. Obesity Res. 1993; 1: 206-22.

40 Popkin BM, Richards MK, Monteiro CA. Stunting is associated with overweight in children of four nations that are undergoing the nutrition transition. $J$. Nutr. 1996; 126 3009-16.

41 Popkin BM, Richards MK, Adair IS. Stunting is associated with child obesity: dynamic relationships, In: Johnston FE, Zemel BS, Eveleth PB, eds. Human Growth and Detelopment, 1998 : Proceedings of the Eighth International Congress of Auxology Philadelphia: Smith-Gordon, forthcoming.

42 Forrester $\mathrm{T}$, Wilks $\mathrm{R}$, Bennett $\mathrm{F}$, et al. Obesity in the Caribbean. In: Chadwick DJ, Cardew G, eds. The Origins and Consequences of Obesity. Ciba Foundation Symposium 201. Chichester, Wiley, 1996: 17-31.

43 Popkin BM. The obesity epidemic is a worldwide phenomenon: trends in transitional societies. Unpublished manuscript, Carolina Population Center, the University of North Carolina at Chapel Hill, 1997

44 Ge K, Weisell R, Guo X, et al. The body mass index of Chinese adults in the 1980s. Eur. J. Clin. Nutr. 1994; 48: S148-S154.

45 United Nations Administrative Commirtee on Coordination, Subcommittee on Nutrition. Update on the Nutrition Situation 1996: Summary of Results for the Third Repon on the World Nutrition Situation. Geneva: ACC/SCN, 1996.

46 Hodge AM, Dowse GK, Gareeboo H, Tuomilehto J, Alberti KGMM, Zimmet PZ. Incidence, increasing prevalence, and predictors of change in obesity and fat distribution over 5 years in the rapidly developing population of Mauritius. Int J. Obesity 1996; 20: 137-46.

47 Hodge AM, Dowse GK. Toelupe P, Collins VR, Zimmet PZ. The association of modernization with dyslipidaemia and changes in lipid levels in the Polynesian population of Western Samoa. Int. J. Epidemiol. 1997; 26: 297-306.

48 World Cancer Research Fund in association with American Institute for Cancer Research. Food, Nutrition and the Pretention of Cancer: a Global Perspective. Washington, DC. American Institute for Cancer Research, 1997.

49 Beaglehole R. Cardiovascular disease in developing countries: an epidemic that can be prevented. $B r . M e d . J .1992$; 305: 1170-1.

50 Byers $\mathrm{T}$, Marshall $\mathrm{J}$. The emergence of chronic diseases in developing countries. SCN News 1995; 13: 14-19.

51 Zimmet PZ. Kelly West Lecture. Challenges in diabetes epidemiology - from west to the rest. Diabetes Care 1991; 15: 232-52.

52 Zimmet PZ, McCarty DJ, de Courten MP. The global epidemiology of non-insulin-dependent diabetes mellitus and the metabolic syndrome. J. Diabet. Comp. 1997; 11: 608.

53 Valdez R, Athens MA, Thompson GH, Bradshaw BS, Stern MP. Birthweight and adult health outcomes in a biethnic population in the USA. Diabetologia 1994; 37; 624.

54 Ford ES, Williamson DF, Liu S. Weight change and diabetes incidence: findings from a national cohort of US adults. Am. J. Epidemiol. 1997; 146: 214-22.

55 O'Dea K, Patel M, Kubisch D, Hopper J, Traianedes, K. Obesity, diabetes, and hyperlipidemia in a Central Australian Aboriginal community with a long history of acculturation. Diabetes Care 1993; 16: 1004-10.

56 Galanis DJ, Sobal J, McGarvey ST, Pelletier DL, Bausserman L. Ten-year changes in the obesity, abdominal adiposity, and serum lipoprotein cholesterol measures of western Samoan men. J. Clin. Epidemiol. 1995; 48: 1485-93.

57 Chadha SL, Radhakrishnan S, Ramachandran K, Kaul U, Gopinath N. Epidemiological study of coronary heart disease in urban population of Delhi. Indian J. Med. Res. 1990; 92: 424-30

58 INCLEN Multicentre Collaborative Group. Risk factors 
for cardiovascular disease in the developing world. A multicentre collaborative study in the International Clinical Epidemiology Network (INCLEN). J. Clin. Epidemiol. 1992; 45: 841-7.

59 Steyn K, Jooste PL, Bourne LT, et al. Risk factors for coronary heart disease in the black population of the Cape Peninsula. The BRISK study. S. Afr. Med. J. 1991; 79: 480-5.

60 Milio N. Nutrition Policy for Food-Rich Countries: a Strategic
Analysis. Baltimore: the Johns Hopkins University Press, 1990.

61 Milio N. Nutrition and health: patterns and policy perspectives in food-rich countries. Soc. Sci. Med. 1989; 29: 413-23.

62 Milio N. Toward healthy longevity: lessons in food and nutrition policy development from Finland and Norway. Scand. J. Soc. Med. 1991; 19: 209-17. 